\title{
Acrylic Customized X-Ray Positioning Stent for Prospective Bone Level Analysis in Long-Term Clinical Implant Studies
}

\author{
Ana Messias*, João Paulo Tondela, Salomão Rocha, Rita Reis, Pedro Nicolau, Fernando Guerra \\ Department of Dentistry, Faculty of Medicine, University of Coimbra, Coimbra, Portugal \\ Email: *ana.messias@uc.pt
}

Received May 16, 2013; revised June 16, 2013; accepted June 23, 2013

Copyright (C) 2013 Ana Messias et al. This is an open access article distributed under the Creative Commons Attribution License, which permits unrestricted use, distribution, and reproduction in any medium, provided the original work is properly cited.

\begin{abstract}
Objectives: This paper describes a technique to produce individualized X-ray positioning devices for intraoral digital imaging of dental implants with long-term stability. Materials and Methods: An X-ray positioning device was built for Gendex ${ }^{\circledR}$ Visualix ${ }^{\circledR}$ eHD sensor, using the Dentsply rinn XCP-DS ${ }^{\circledR}$ system individualized by the incorporation of the bite piece within an acrylic stent to perform successive standardized radiographs to 16 patients. X-ray tube stabilization was achieved with polivinylsiloxane. Series of 3 radiographs were taken to each patient in different moments. Specific linear measurements as the implant diameter (mesio-distal width) and the height between consecutive threads (thread pitch) were made to all radiographs to determine the reproducibility and accuracy of the procedure. Results: The intraclass correlation coefficient for the mesio-distal width was 0.964 [(0.920 - 0.986) 95\% CI] (p < 0.01) and 0.990 [ $(0.976$ - 0.996) $95 \% \mathrm{CI}](\mathrm{p}<0.01)$ for the thread pitch. Bland-Altman plots comparing implant diameter showed mean bias of $0.01 \pm 0.01975,0.01 \pm 0.02243$ and $0.0006 \pm 0.025$ for groups $1-2,1-3$ and $2-3$ respectively. Mean bias of $0.0024 \pm$ $0.00552,0.0027 \pm 0.00552$ and $0.0003 \pm 0.0012$ was found for the thread pitch analysis of groups $1-2,1-3$ and $2-3$. One sample t-test for trueness of mesio-distal width, thread pitch and ratio showed mean difference of $0.00156 \mathrm{~mm}$ for the test value of $3.3(\mathrm{p}=0.9),-0.00026 \mathrm{~mm}$ for $0.8(\mathrm{p}=0.96)$ and 0.0124 for $4.125(\mathrm{p}=0.72)$, respectively, after the application of a magnification correction factor. Conclusion: The device produced reproducible images in different moments and was suitable for comparative clinical examinations of marginal bone as it was convenient to perform reliable linear measurements.
\end{abstract}

Keywords: Dental Radiovisiography; Radiograph; Dental Implant; Outcome Measurement Errors; Reproducibility of Results

\section{Introduction}

Long-term evaluation of dental implants and their surrounding structures is crucial to provide more information concerning the success or failure of these therapies in clinical trials. The radiographic analysis, in conjunction with the clinical evaluation of the implant sites, is the best non-invasive method for bone level determination [1-4]. Among the diverse radiographic techniques, the periapical technique has proven to be the most accurate method for the linear measurement of alveolar bone height [5-7]. However, the diagnosis of progressive bone loss or the identification of bone gain from one radiographic examination to the next may be very difficult to interpret due to errors in the alignment of successive im-

\footnotetext{
${ }^{*}$ Corresponding author.
}

ages. This, together with intra and inter-examiner variability, leads to incorrect interpretations of bone height and density changes, and limits the diagnostic value of conventional periapical radiographs, especially in cancellous bone [8-11].

To overcome this problem, Updegrave [12] detailed the paralleling extension-cone technique and introduced the Rinn system, the first film holder to keep the film parallel to the tooth and in a flat position, but still not producing acceptable images for continuous reproduction. Ever since, numerous systems have been proposed to obtain superimposable dental radiographs but have not proven to prevent projection errors effectively as they fail to ensure the realignment of the initial imaging geometry [13-21]. The two main sources of differences in the projection geometry between pairs of radiographs 
arise due to the differences in the relationships between either the object and the radiographic film/sensor, or the object and the X-ray source [9,22]. While the first can be solved using a film or sensor holder placed within a rigid bite stent that facilitates consistent positioning of the film behind a group of teeth, the second cannot be so easily addressed $[23,24]$. Nevertheless, reproducible alignments are achievable by fixing the patient's head to the tube head using some forms of extra-oral apparatus, as the metallic tip of the Dentsply Rinn XCP ${ }^{\circledR}$ system (Dentsply Rinn, Elgin, IL) that promotes the perpendicular position of the central X-ray to the film plane. The most important feature is to prevent changes in the projection geometry between consecutive radiographs, as they are responsible for irreversible distortions that may lead to different twodimensional images of the same clinical three-dimensional situation $[5,8,10]$.

Even though perfect parallelism between the object and the film plane is not always achievable under clinical conditions, consistent projection geometry has been referred as the most important feature for correct bone level assessment. Several systems have been described previously in the literature for the standardization of conventional periapical radiographs [13-19,21] but lack the needed and yearning accuracy.

Considering the widespread of radiovisiography and the need for repeatable images prone to further digital imaging treatment as linear measurement or DSR, the authors firstly propose to report an improved technique to attain standardization of serial radiographs with geometric projection matching and minimization of the distortion of structures, which allows the isolation of the area of interest, the superimposition of structures such as teeth, implants and bone, and facilitates the quantification of peri-implant bone level changes. Secondly, the authors aim at the determination of the reliability and trueness of the described device.

\section{Materials and Methods}

\subsection{Clinical and Laboratorial Procedures}

Sixteen patients enrolled for a non-interventional clinical study with Straumann Roxolid ${ }^{\circledR}$ Bone Level implants (Institute Straumann AG, Waldenburg/BL, Switzerland) authorized by the Committee for Ethics in Health of the University Hospital of Coimbra-Portugal-were selected for the build up of an X-ray standardization appliance. The proposed device is a modification of the Han-Shin type positioner for the periapical technique $[14,15]$ that uses the Dentsply rinn XCP-DS ${ }^{\circledR}$ system adapted for the Gendex ${ }^{\circledR}$ Visualix ${ }^{\circledR}$ eHD (Gendex Dental Systems, IL, USA) universal size sensor $(37.5 \mathrm{~mm} \times 25.5 \mathrm{~mm})$. The system is composed of a plastic bite piece, a sensor holder, a metallic arm and a plastic aiming ring for ori- entation of the tube head cylinder. Both bite block and the aiming ring are individualized for each patient, which requires two appointments.

In the first appointment, impressions from the upper and lower arch are made using alginate impressions.

The alginate impressions are filled with dental plaster and the stone models obtained are mounted according to jaw relation onto the semi-adjustable articulator.

A bilateral acrylic block is built over the arch with the area of interest; for instance, if the area is on the lower jaw, the acrylic block is built over the mandibular teeth. The bite plastic piece, the sensor basket and a sensor replica (with the same size as the sensor) are placed over the cured acrylic block ensuring that the sensor replica is parallel to the area of interest and acceptable mouth opening is checked (Figures 1 and 2). The bite piece, the sensor holder and replica are held against the opposite dental arch and stabilized bilaterally with acrylic (Figure 3). The result, after cure, is a bimaxillary splint that ensures the reproducibility of the intra-oral sensor orientation in sequential radiographs (Figures 4-6).

\subsection{Series of Radiographs}

Series of radiographs were taken for all the patients using the Gendex ${ }^{\circledR}$ Visualix ${ }^{\circledR}$ eHD universal size sensor at the

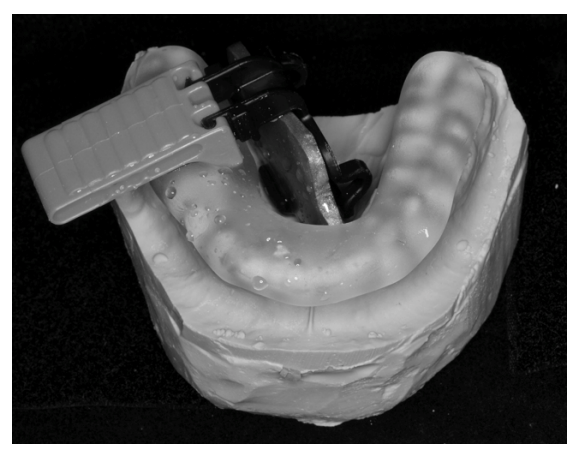

Figure 1. Sensor replica and horizontal basket set with the plastic bite piece and placed parallel to the region of interest (upper view).

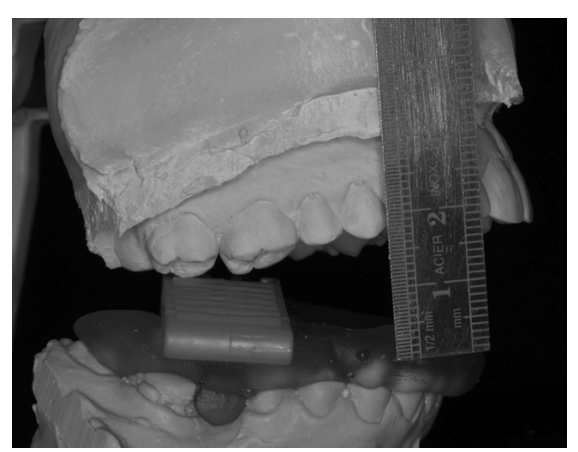

Figure 2. The plastic bite piece is held against the opposite arch teeth. Mouth aperture is checked to ensure that the patient supports the splint. 


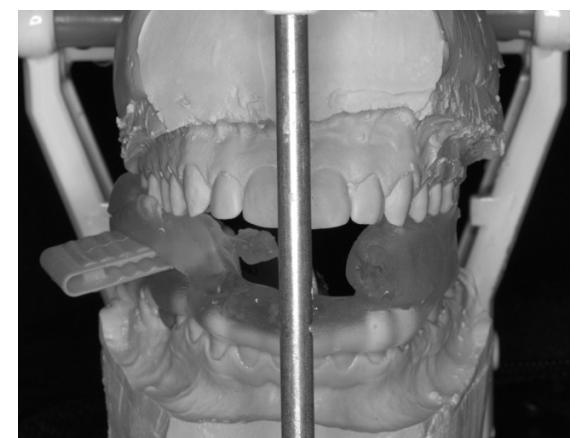

Figure 3. Bilateral bite block frontal view after cure.

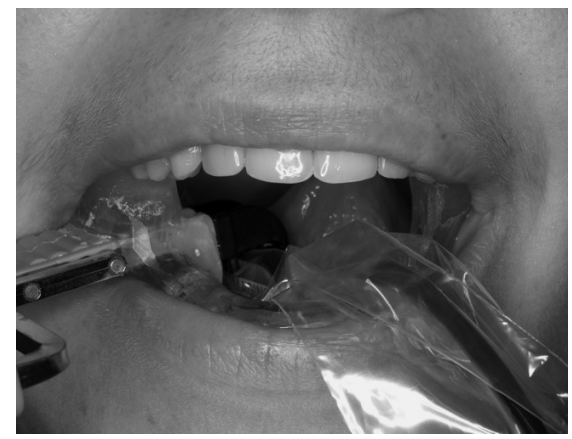

Figure 4. Device try-in with sensor placed in basket. The acrylic block is seated over the mandibular teeth. Afterwards the patient fits the maxillary teeth in the splint and stabilizes the device.

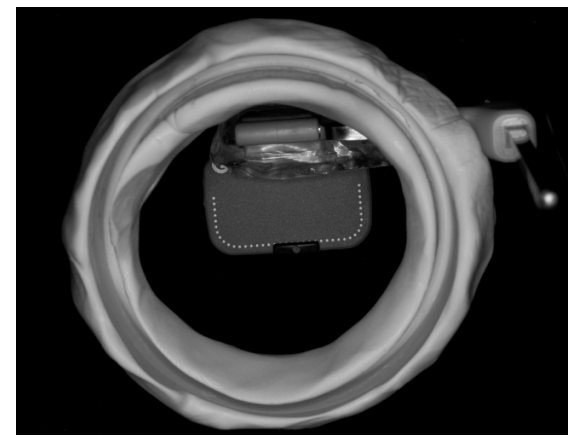

Figure 5. After the try-in, the aiming ring is individualized with silicone putty to keep the tube cylinder stable and perpendicular to the sensor.

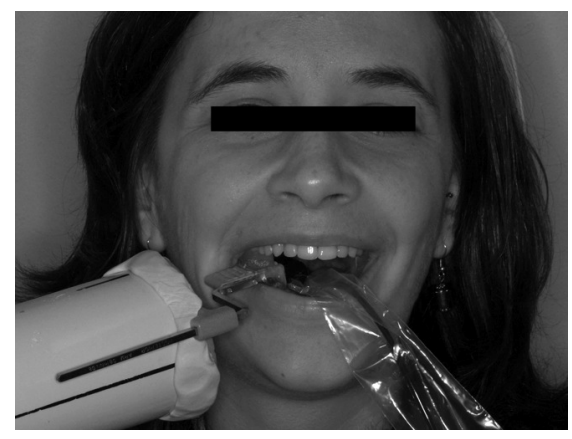

Figure 6. Frontal view of the complete set up in the mouth and with the cylinder tube fixed. maximum image resolution of $25.6 \mathrm{LP} / \mathrm{mm}$ to assess the reproducibility of the procedure at distinct times: baseline, implant surgery, rehabilitation and first year (after surgery). Figure 7 is representative of the series of radiographs; image size considered was $1590 \times 1024$ pixels. All patients signed an informed consent form.

\subsection{Statistical Analysis}

To determine the accuracy and repeatability of the digital images obtained through the standardization method, series of repeated measurements were obtained from the 16 clinical situations of areas with Straumann Roxolid ${ }^{\circledR}$ Bone Level implants (Institute Straumann AG, Waldenburg/BL, Switzerland) by a professional trained in implant therapy and radiographic analysis of dental implants using the ruler tool of the VixWin ${ }^{\mathrm{TM}}$ Platinum (Gendex Dental Systems, IL, USA) imaging software. Thus, for each clinical situation specific points were identified in the threads of the implants of the first radiograph of the series and the mesio-distal length (diameter) and the thread pitch registered in the same conditions for all three images, as represented in Figure 8. Radiographs were taken at the surgery (initial moment) (group 1), rehabilitation (3rd - 4th month) (group 2) and control (1st year) (group 3) and the results were analyzed with the PASW $^{\circledR}$ Statistics 18 (IBM). To determine agreement of the measurements of the 3 moments, intraclass correlation coefficients (ICC) were calculated based on the two-way mixed model using an absolute agreement definition for single measures and Bland-Altman plots were built for both the mesio-distal length and for the thread pitch height of the implants (95\% Limit of Agreement) [25]. The first accounts for the evaluation of magnification errors from one image to the next while the second determines variations of the projection geometry between successive images. Variations in the beam-object-sensor angulations result in distortion of the implants detectable by thread height reduction or elongation. Overall image distortion was determined by calculating a new variable was computed to determine the ratio between the mesiodistal length and the thread pitch. A relationship proximal to the theoretical value for the ratio demonstrates the same proportionality of the implant, confirming low distortion and correct angular projection. The values were analyzed with the one sample t-test to $(95 \% \mathrm{CI})$ to compare the mean difference between each value and the standard value for the implant diameter, for the thread pitch and the ratio. Values are expressed in millimeters.

\section{Results}

The setup described guarantees even projection geometry in sequential radiographs, regardless the head position ofthe patient. The X-ray cone-area of interest-sensor angu- 

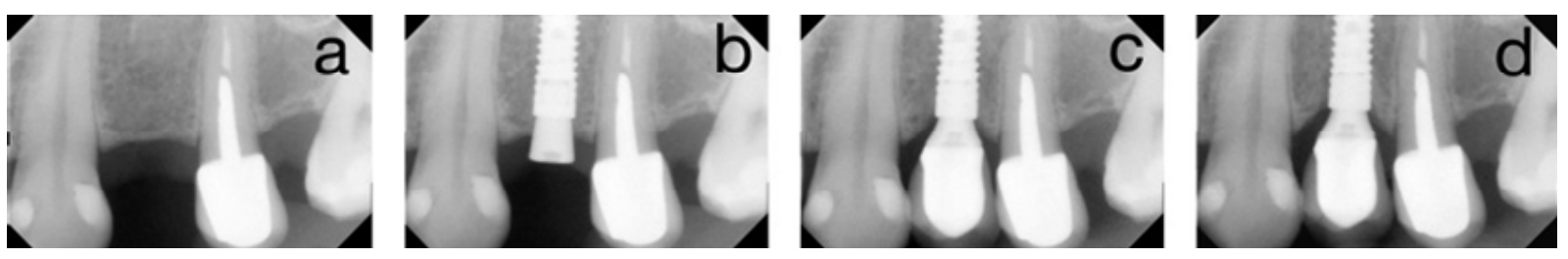

Figure 7. Tooth 24 area: a) pre-operatory; b) surgery; c) definitive restoration; d) 1 year follow-up.

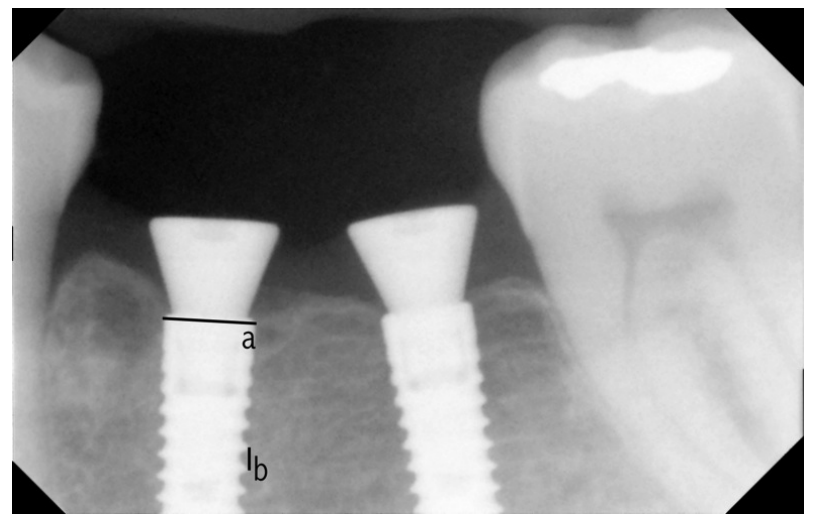

Figure 8. Representation of the method used for measurements acquisition. a: Acquisition of the Mesio-Distal (MD) length; b: Acquisition of the thread pitch.

lation is determined by the fixation of the plastic bite with rigid acrylic and by the silicone putty individualized aiming ring.

Table 1 summarizes the descriptive statistics for the differences between pairs of groups for implant diameter and thread pitch height. Reliability analysis for the implant diameter revealed an ICC of 0.964 [(0.920 - 0.986) $95 \% \mathrm{CI}]$ calculated for single measures of the three groups using the absolute agreement definition $(\mathrm{p}<0.01)$. Intraclass correlation coefficient determined for the thread measurements was 0.990 [(0.976 - 0.996) $95 \% \mathrm{CI}]$ $(\mathrm{p}<0.01)$. Figure 9 represents the Bland-Altman plot for the agreement of the paired groups $1-2,1-3$ and $2-3$ regarding the differences in thread pitches between radiographs. The values of the three groups for mesio-distal length, thread pitch and mesio-distal length to thread pitch ratio were gathered into a single group with correspondence. These three groups with 48 values each were compared to the respective reference values. The real implant diameter of $3.3 \mathrm{~mm}$ and the real thread pitch value of $0.8 \mathrm{~mm}$ were obtained from the manufacturer catalog. The determined reference ratio was 4.125 and the results are summarized in Table 2; $p$ values stand for the one sample t-test results for the comparison of the group means with the reference values provided to test for the trueness of the standardization method. No significant differences were found $(\mathrm{p}>0.05)$. The mean difference of the measured values and the reference values was negligible for all three groups. Single measurements range from the real value $(95 \% \mathrm{CI})$ : $[-0.0234$,

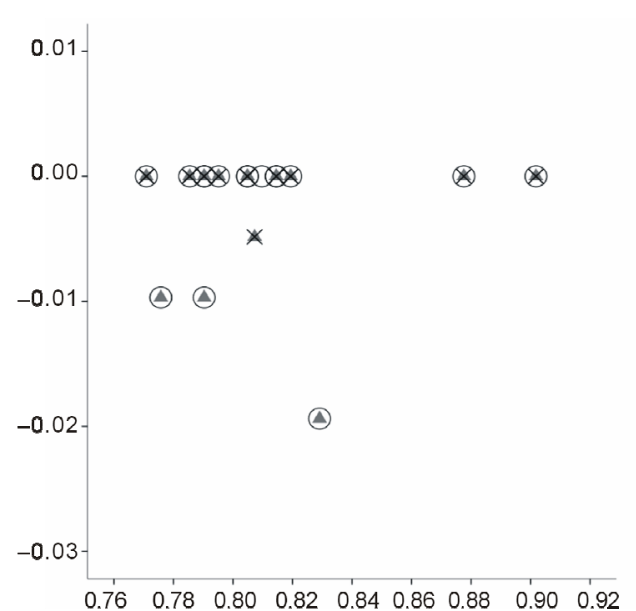

Figure 9. Bland-Altman plot of thread height measurements for groups 1 and $2 ; 1$ and $3 ; 2$ and 3. Mean differences between groups of $-0.0024 \mathrm{~mm},-\mathbf{0 . 0 0 2 7} \mathrm{mm}$ and $0.0003 \mathrm{~mm}$, respectively.

Table 1. Descriptive statistics for bias between measurements (mm). Min-minimum; Max-maximum; SDStandard Deviation.

\begin{tabular}{cccc}
\hline & Mean \pm SD & $\begin{array}{c}\text { Mean } \\
\text { difference }\end{array}$ & $\mathbf{p}$ \\
\hline MD width (3.3) & $3.3016 \pm 0.08611$ & 0.00156 & 0.9 \\
Thread pitch (0.8) & $0.7997 \pm 0.03385$ & -0.00026 & 0.96 \\
MD/Thread ratio (4.125) & $4.1374 \pm 0.23446$ & 0.0124 & 0.72 \\
\hline
\end{tabular}

Table 2. Mean \pm SD for MD width, thread pitch and MD/Pitch ratio error and one sample sample t-test $(\alpha=$ 0.05). Bracket values represent the reference values for the t-test. SD—-standard deviation.

\begin{tabular}{ccccc}
\hline & & Min & Max & Mean \pm SD \\
\hline \multirow{2}{\text{Implant}}{ Diameter } & Group 1 and 2 & 0.00 & 0.06 & $0.0100 \pm 0.01975$ \\
& Group 1 and 3 & -0.02 & 0.06 & $0.0100 \pm 0.02243$ \\
& Group 2 and 3 & -0.06 & 0.06 & $0.0006 \pm 0.02542$ \\
$\begin{array}{c}\text { Thread } \\
\text { Pitch }\end{array}$ & Group 1 and 2 & 0.00 & 0.02 & $0.0024 \pm 0.00552$ \\
Height & Group 1 and 3 & 0.00 & 0.02 & $0.0027 \pm 0.00552$ \\
& Group 2 and 3 & 0.00 & 0.00 & $0.0003 \pm 0.00120$ \\
\hline
\end{tabular}

$0.0266 \mathrm{~mm}]$ for the MD width, $[-0.0101,0.0096]$ for the thread height and $[-0.0557,0.0805]$ for the ratio. 


\section{Discussion}

Presently in clinical practice, alveolar bone loss is assessed either by measuring the linear crestal bone height from sequential radiographs or by density methods as DSR $[3,19,26]$. These methods are easily influenced by changes on the projection geometry of successive periapical radiographies as it affects the image of anatomical structures superimposed and constrains variations of the trabecular pattern of the cancellous bone. Moreover, the artifacts created by the high radiographic opacity of the dental implants, together intra and interexaminer variability, limit the diagnostic value of conventional radiographs with uncontrolled angular variations [27-29].

Differences in the projection angles between consecutively obtained radiographs has a distorting effect that leads to misinterpretations of bone levels $[10,23,24,30]$. Hence, X-ray standardization and the degree to which all details can be superimposed is critical for the correct evaluation of bone levels and density changes between consecutive images, which is particularly true at the alveolar crest $[3,15,31]$. Despite being the most recommended system to attain X-ray standardization, the XCP system does not permit reproducible film placement or image density normalization by itself $[6,16,20]$. Consistent film or sensor to area of interest alignment can only be achieved through the cross-arch stabilization design of the described splint that incorporates the XCP bite block and establishes the exact position of the film or sensor for each follow-up examination, eliminating this source of misalignments. Unilateral bite registrations with non-rigid materials allow small horizontal and vertical planar rotations of the detector relative to the object, deteriorate over time and are a source of distortion. Some authors even refer no improvement in the measurements of bone levels using silicone-based bite blocks $[13,32]$. Even though other articles refer that alignment software overcomes these kind of planar errors after image capture by mathematical correction of the image with basis on the implant size, it is still advisable that, as discussed previously, all sources of object-detector angulations are eliminated $[24,33]$. Thus, considering the use of a rigid splint to position the sensor, the orientation of the X-ray beam is responsible for the largest source of distortion and irreversible misalignment. In fact, the angulation difference between the central beam and the detector holder is more important for the interpretation of radiographic changes than the angulations between the detector and the area of interest $[11,34]$. To reduce irreversible alignment errors, several methods with beam aiming devices have been proposed, including the use of cephalostats with increased source-object distance, opto-electronic positioning devices and some sort of "film holder to radiation source" connections. Whereas the two first require difficult procedures that demand for special equipment, the other connections are lighter and simpler to use, as the XCP Rinn metallic arm and aiming ring used in this work $[3,10,13,14,17-19,35]$. The rigidity of the X-ray coupling to the film holder has been issue of debate. Some authors argue that a rigid connection may cause tilting between the splint and the teeth that is difficult to control $[10,26,36]$. However, non-rigid coupling to the X-ray cone seems to be the largest source of alignment error $[9,22,30,34]$. The individualization of the aiming ring with silicone putty presented in this paper is, in fact, an improvement to the technique described by Couture, Dixon [15] that gives rigidity to the connection, assures unchallenging stability of the projection and prevents magnification errors between successive radiographs. The ICC of 0.990 [(0.976 - 0.996) $95 \% \mathrm{CI}]$ for the thread width measurements for the three moments clearly estimates a strong correlation between measurements, therefore stating the high reproducibility of the method with regard to changes in the vertical angulations. The mean bias of $0.0024 \mathrm{~mm}[(-0.0084,0.0132) 95 \% \mathrm{CI}]$ for the same measurements of groups 1 and 2, 0.0027 $\mathrm{mm}[(-0.0081,0.0135) 95 \% \mathrm{CI}]$ for groups 1 and 3 and $0.0003 \mathrm{~mm}[(-0.0020,0.0026) 95 \% \mathrm{CI}]$ for groups 2 and 3 , is perfectly acceptable considering the implant manufacturing tolerance of 0.01 to 0.001 inches $(0.0254$ to $0.254 \mathrm{~mm}$ ). Bland-Altman plots represented in Figure 9 present small discrepancy between thread pitch measurements, 0 bias for the majority of pairs of measurements and very few values per graphic out of the $95 \%$ limit of agreement, revealing negligible discrepancy between pairs of images. Accordingly, the ICC of 0.964 $[(0.920-0.986) 95 \% \mathrm{CI}]$ tested for the reliability of implant diameter measurements shows that magnification variations between pairs of radiographs are virtually eliminated through the presented method, which is in line with the results of previous studies using the XCP Rinn system [16]. More, the method has proven to be accurate as no significant differences were found among the mean mesio-distal linear measurements and the real implant diameter $(3.3 \mathrm{~mm})(\mathrm{p}=0.9)$, and the mean thread height and the real thread pitch $(0.8 \mathrm{~mm})(\mathrm{p}=0.96)$, both with negligible differences between each value and the reference value.

The $\mathrm{MD} /$ pitch ratio calculated for each radiograph and its comparison to the reference value of 4.125 aimed at the determination of the mean distortion of the image caused by violation of the principles of the parallelism technique. Seeing that the sensor holder and the metallic tip provide the required perpendicularity between the cone and the sensor, the referred distortion is triggered by non-perpendicular alignment of the X-ray source and the region of interest containing the implant. In spite of the slightly higher mean difference of the measurements to the value of the real ratio $(0.0124 \mathrm{~mm})$, all measure- 
ments demonstrated to be precise, denoting no misrepresented images of the implants. This, in conjunction with the MD width and thread pitch analysis, reinforces the validity of the method to carry out linear measurements for bone level assessment over implant radiographs.

\section{Conclusion}

Highly standardized radiographs allow for accurate linear evaluation of crestal bone regardless the observer and are of greatest importance for the diagnostic value of densitometry and subtraction techniques as the projection geometry is controlled and a reproducible alignment is achieved for long term follow-up. The template here described for X-ray standardization is adapted from a commercially available system meant for radiovisiography. It consists of a rigid sensor holder-object-X-ray source type of device with a custom-made acrylic bite-block attached to the sensor holder and connected to the tube through an individualized aiming ring. This X-ray alignment device minimizes variations in X-ray imaging geometry caused by different angulations between the central beam and the region of interest and prevents angular distortion and alignment errors between two consecutive radiographs, thus making matching images that are superimposable, which allows a quantitative analysis of longitudinal radiographic crestal bone changes.

\section{Acknowledgements}

The authors would like to express their gratitude to Anabela Pedroso, Laboratory Technician of the Department of Dentistry, Faculty of Medicine, University of Coimbra, for her continuous and valuable work on the elaboration of the acrylic stents.

\section{REFERENCES}

[1] L. Laurell, and D. Lundgren, "Marginal Bone Level Changes at Dental Implants after 5 Years in Function: A Meta-Analysis," Clinical Implant Dentistry and Related Research, Vol. 13, No. 1, 2011, pp. 19-28. doi:10.1111/j.1708-8208.2009.00182.x

[2] M. P. Hanggi, D. C. Hanggi, J. D. Schoolfield, J. Meyer, D. L. Cochran and J. S. Hermann, "Crestal Bone Changes around Titanium Implants. Part I: A Retrospective Radiographic Evaluation in Humans Comparing Two NonSubmerged Implant Designs with Different Machined Collar Lengths," Journal of Periodontology, Vol. 76, No. 5, 2005, pp. 791-802. doi:10.1902/jop.2005.76.5.791

[3] J. S. Hermann, J. D. Schoolfield, P. V. Nummikoski, D. Buser, R. K. Schenk and D. L. Cochran, "Crestal Bone Changes around Titanium Implants: A Methodologic Study Comparing Linear Radiographic with Histometric Measurements," The International Journal of Oral \& Maxillofacial Implants, Vol. 16, No. 4, 2001, pp. 475485.
[4] F. Isidor, "Clinical Probing and Radiographic Assessment in Relation to the Histologic Bone Level at Oral Implants in Monkeys," Clinical Oral Implants Research, Vol. 8, No. 4, 1997, pp. 255-264.

doi:10.1034/j.1600-0501.1997.080402.x

[5] M. Wakoh, et al., "Reliability of Linear Distance Measurement for Dental Implant Length with Standardized Periapical Radiographs," The Bulletin of Tokyo Dental College, Vol. 47, No. 3, 2006, pp. 105-115.

doi: $10.2209 /$ tdcpublication.47.105

[6] E. De Smet, R. Jacobs, F. Gijbels and I. Naert, "The Accuracy and Reliability of Radiographic Methods for the Assessment of Marginal Bone Level around Oral Implants," Dentomaxillofacial Radiology, Vol. 31, No. 3, 2002, pp. 176-181. doi:10.1038/sj.dmfr.4600694

[7] H. J. Meijer, W. H. Steen and F. Bosman, "A Comparison of Methods to Assess Marginal Bone Height around Endosseous Implants," Journal of Clinical Periodontology, Vol. 20, No. 4, 1993, pp. 250-253. doi:10.1111/j.1600-051X.1993.tb00353.x

[8] K. H. Huh, S. S. Lee, I. S. Jeon, W. J. Yi, M. S. Heo and S.C. Choi, "Quantitative Analysis of Errors in Alveolar Crest Level Caused by Discrepant Projection Geometry in Digital Subtraction Radiography: An in Vivo Study," Oral Surgery, Oral Medicine, Oral Pathology, Oral Radiology, Vol. 100, No. 6, 2005, pp. 750-755. doi:10.1016/j.tripleo.2005.03.005

[9] A. Mol and S. M. Dunn, "The Performance of Projective Standardization for Digital Subtraction Radiography," Oral Surgery, Oral Medicine, Oral Pathology, Oral Radiology, Vol. 96, No. 3, 2003, pp. 373-382. doi:10.1016/S1079-2104(03)00357-3

[10] P. Eickholz, T. S. Kim, D. K. Benn and H. J. Staehle, "Validity of Radiographic Measurement of Interproximal Bone Loss," Oral Surgery, Oral Medicine, Oral Pathology, Oral Radiology, Vol. 85, No. 1, 1998, pp. 99-106. doi:10.1016/S1079-2104(98)90406-1

[11] D. K. Benn, "Estimating the Validity of Radiographic Measurements of Marginal Bone Height Changes around Osseointegrated Implants," Implant Dentistry, Vol. 1, No. 1, 1992, pp. 79-83. doi:10.1097/00008505-199200110-00008

[12] W. J. Updegrave, "The Paralleling Extension-Cone Technique in Intraoral Dental Radiography," Oral Surgery, Oral Medicine, Oral Pathology, Vol. 4, No. 10, 1951, pp. 1250-1261. doi:10.1016/0030-4220(51)90084-9

[13] N. Fernandez-Formoso, B. Rilo, M. J. Mora, I. Martinez-Silva and U. Santana, "A Paralleling Technique Modification to Determine the Bone Crest Level around Dental Implants," Dentomaxillofacial Radiology, Vol. 40, No. 6, 2011, pp. 385-389. doi:10.1259/dmfr/45365752

[14] R. L. Navarro, P. V. Oltramari, J. F. Henriques, A. L. Capelozza, E. Santana and J. M. Granjeiro, "Radiographic Techniques for Medical-Dental Research with Minipigs," The Veterinary Journal, Vol. 174, No. 1, 2007, pp. 165-169. doi:10.1016/j.tvj1.2006.06.004

[15] R. A. Couture, D. A. Dixon and C. F. Hildebolt, "A Precise Receptor-Positioning Device for Subtraction Radiography, Based on Cross-Arch Stabilization," Dentomax- 
illofacial Radiology, Vol. 34, No. 4, 2005, pp. 231-236. doi: $10.1259 / \mathrm{dmfr} / 22285074$

[16] D. A. Dixon and C. F. Hildebolt, "An Overview of Radiographic Film Holders," Dentomaxillofacial Radiology, Vol. 34, No. 2, 2005, pp. 67-73. doi: $10.1259 / \mathrm{dmfr} / 99945885$

[17] J. C. Wu, et al., "Use of a Simple Intraoral Instrument to Standardize Film Alignment and Improve Image Reproducibility," Oral Surgery, Oral Medicine, Oral Pathology, Oral Radiology, Vol. 100, No. 1, 2005, pp. 99104. doi:10.1016/j.tripleo.2004.12.011

[18] C. Morea, et al., "Development of an Opto-Electronic Positioning Device for Serial Direct Digital Images of Oral Structures," Journal of Periodontal Research, Vol. 35, No. 4, 2000, pp. 225-231. doi:10.1034/j.1600-0765.2000.035004225.x

[19] E. D. Kuhl and P. V. Nummikoski, "Radiographic Absorptiometry Method in Measurement of Localized Alveolar Bone Density Changes," Oral Surgery, Oral Medicine, Oral Pathology, Oral Radiology, Vol. 89, No. 3, 2000, pp. 375-381. doi:10.1016/S1079-2104(00)70105-3

[20] T. E. Southard, D. M. Wunderle, K. A. Southard and J. R. Jakobsen, "Geometric and Densitometric Standardization of Intraoral Radiography through Use of a Modified XCP System," Oral Surgery, Oral Medicine, Oral Pathology, Oral Radiology, Vol. 87, No. 2, 1999, pp. 253-257. doi:10.1016/S1079-2104(99)70281-7

[21] B. Dubrez, S. Jacot-Descombes and G. Cimasoni, "Reliability of a Paralleling Instrument for Dental Radiographs," Oral Surgery, Oral Medicine, Oral Pathology, Oral Radiology, Vol. 80, No. 3, 1995, pp. 358-364. doi:10.1016/S1079-2104(05)80395-6

[22] B. J. Potter, M. K. Shrout and J. C. Harrell, "Reproducibility of Beam Alignment Using Different Bite-Wing Radiographic Techniques," Oral Surgery, Oral Medicine, Oral Pathology, Oral Radiology, Vol. 79, No. 4, 1995, pp. 532-535. doi:10.1016/S1079-2104(05)80141-6

[23] R. Schulze, D. D. Bruellmann, F. Roeder and B. d'Hoedt, "Determination of Projection Geometry from Quantitative Assessment of the Distortion of Spherical References in Single-View Projection Radiography," Medical Physics, Vol. 31, No. 10, 2004, pp. 2849-2854. doi:10.1118/1.1796951

[24] R. K. Schulze and B. d'Hoedt, "Mathematical Analysis of Projection Errors in 'Paralleling Technique' with Respect to Implant Geometry," Clinical Oral Implants Research, Vol. 12, No. 4, 2001, pp. 364-371. doi:10.1034/j.1600-0501.2001.012004364.x

[25] J. M. Bland and D. G. Altman, "A Note on the Use of the Intraclass Correlation Coefficient in the Evaluation of Agreement between Two Methods of Measurement," Computers in Biology and Medicine, Vol. 20, No. 5, 1990, pp. 337-340. doi:10.1016/0010-4825(90)90013-F

[26] U. Bragger, L. Pasquali, H. Rylander, D. Carnes and K. S. Kornman, "Computer-Assisted Densitometric Image Analysis in Periodontal Radiography. A Methodological Study," Journal of Clinical Periodontology, Vol. 15, No. 1, 1988, pp. 27-37.
doi:10.1111/j.1600-051X.1988.tb01551.x

[27] A. Kavadella, A. Karayiannis and K. Nicopoulou-Karayianni, "Detectability of Experimental Peri-Implant Cancellous Bone Lesions Using Conventional and Direct Digital Radiography," Australian Dental Journal, Vol. 51, No. 2, 2006, pp. 180-186. doi:10.1111/j.1834-7819.2006.tb00424.x

[28] M. Christgau, K. A. Hiller, G. Schmalz, C. Kolbeck and A. Wenzel, "Quantitative Digital Subtraction Radiography for the Determination of Small Changes in Bone Thickness: An in Vitro Study," Oral Surgery, Oral Medicine, Oral Pathology, Oral Radiology, Vol. 85, No. 4, 1998, pp. 462-472. doi:10.1016/S1079-2104(98)90076-2

[29] M. Christgau, K. A. Hiller, G. Schmalz, C. Kolbeck and A. Wenzel, "Accuracy of Quantitative Digital Subtraction Radiography for Determining Changes in Calcium Mass in Mandibular Bone: An in Vitro Study," Journal of Periodontal Research, Vol. 33, No. 3, 1998, pp. 138-149. doi:10.1111/j.1600-0765.1998.tb02304.x

[30] I. P. Sewerin, "Errors in Radiographic Assessment of Marginal Bone Height around Osseointegrated Implants," Scandinavian Journal of Dental Research, Vol. 98, No. 5, 1990, pp. 428-433. doi:10.1111/j.1600-0722.1990.tb00994.x

[31] U. E. Ruttimann, R. L. Webber and E. Schmidt, "A Robust Digital Method for Film Contrast Correction in Subtraction Radiography," Journal of Periodontal Research, Vol. 21, No. 5, 1986, pp. 486-495. doi:10.1111/j.1600-0765.1986.tb01484.X

[32] T. A. Larheim and S. Eggen, "Measurements of Alveolar Bone Height at Tooth and Implant Abutments on Intraoral Radiographs. A Comparison of Reproducibility of Eggen Technique Utilized with and without a Bite Impression," Journal of Clinical Periodontology, Vol. 9, No. 3, 1982, pp. 184-192. doi:10.1111/j.1600-051X.1982.tb02058.x

[33] T. Economopoulos, G. K. Matsopoulos, P. A. Asvestas, K. Grondahl and H. G. Grondahl, "Automatic Correspondence Using the Enhanced Hexagonal Centre-Based Inner Search Algorithm for Point-Based Dental Image Registration," Dentomaxillofacial Radiology, Vol. 37, No. 4, 2008, pp. 185-204. doi:10.1259/dmfr/26553364

[34] F. Roeder, D. Brullmann, B. d'Hoedt and R. Schulze, " $E x$ Vivo Radiographic Tooth Length Measurements with the Reference Sphere Method (RSM)," Clinical Oral Investigations, Vol. 14, No. 6, 2010, pp. 645-651. doi:10.1007/s00784-009-0350-9

[35] A. Rawlinson, et al., "An in-Vitro and in-Vivo Methodology Study of Alveolar Bone Measurement Using Extra-Oral Radiographic Alignment Apparatus, Image ProPlus Software and a Subtraction Programme," Journal of Dentistry, Vol. 33, No. 9, 2005, pp. 781-788. doi:10.1016/j.jdent.2005.01.013

[36] D. K. Benn, "Limitations of the Digital Image Subtraction Technique in Assessing Alveolar Bone Crest Changes Due to Misalignment Errors During Image Capture," Dentomaxillofacial Radiology, Vol. 19, No. 3, 1990, pp. 97-104. 